\title{
Fahr's Disease Presenting with Manic Symptoms
}

\author{
Sandip Subedi, ${ }^{1}$ Sadan Mukhi, ${ }^{2}$ Pradip Pandey ${ }^{3}$ \\ 'Department of Psychiatry, Universal College of Medical Sciences, Bhairahawa, Nepal, ${ }^{2}$ Department of Radiology, \\ Universal college of Medical Sciences, Bhairahawa, Nepal, ${ }^{3}$ Department of Psychiatry, Universal college of Medical \\ Sciences, Bhairahawa, Nepal.
}

\section{ABSTRACT}

Bilateral striopallidodentate calcinosis, commonly known as Fahr's disease, is a rare syndrome characterised by symmetrical calcification over the basal ganglion and dentate nucleus. No case of Fahr's disease with associated manic symptoms has been described in the literature to date. We report an unusual case of Fahr's Disease in a 18 year old unmarried male who presented to the emergency department of Universal College of Medical Sciences - Teaching Hospital, Nepal with symptoms of mania. Computed tomographic scan of the patient demonstrated extensive symmetrical calcification over the basal ganglia and dentate nuclei. No underlying cause for the bilateral calcification was found. This rare case of Fahr's disease, which has never been reported in Indian literature has been reported to highlight this unusual condition and its differentiation from the commoner Fahr's syndrome.

Keywords: Fahr's disease; mania; basal ganglia.

\section{INTRODUCTION}

Fahr's disease, is a rare neurologic disorder of unknown etiology characterized by neuropsychiatric abnormalities, parkinsonian or choreoathetotic type movement disturbances and extensive symmetrical calcification of the basal ganglia and dentate nuclei in the cerebellum. ${ }^{1}$ No case of Fahr's disease with associated manic symptoms has been described in the literature to date.

We report a case of Fahr's disease in a 18 year male who presented with symptoms of mania.

\section{CASE REPORT}

An 18 years old unmarried, hindu, male, student from Pyuthan presented to the Emergency Department of UCMS-TH, Nepal with chief complaints of irritability and abusiveness. On detailed history taking it was found that the illness started two months prior after he failed in the XII standard final examination. Symptoms begun acutely with insomnia and irritability. Gradually, patient started becoming overfamiliar, overtalkative and stubborn. He would make big business plans and roam around the whole day. The predominant mood was euphoric but would become irritable when others object on his plans and behaviours. There was no similar or other neuropsychiatric illness in the past. There was no history of head injury nor any chronic physical illness. Family history was insignificant. There was no history of substance use and patient was well- adjusted premorbidly.

There was no abnormal findings in general physical examination and systemic examination including CNS. Mental state examination revealed increased psychomotor activity, not-established rapport, increased speech production with decreased reaction time. There was increased production of thought with increased self-confidence and delusion of grandiosity.

Correspondence: Dr. Sandip Subedi, Department of Psychiatry Universal college of Medical Sciences, Bhairahawa, Nepal. Email: sandipsubedi@hotmail.com, Phone: +977-9857035021. 
Baseline investigations were within normal range. Serum parathyroid level and thyroid function test was normal. Chest X-ray and ultrasonography of abdomen was normal. CT scan (brain) revealed dense calcification in head of caudate nucleus, basal ganglia, thalamus and frontal cortex (Figure 1).

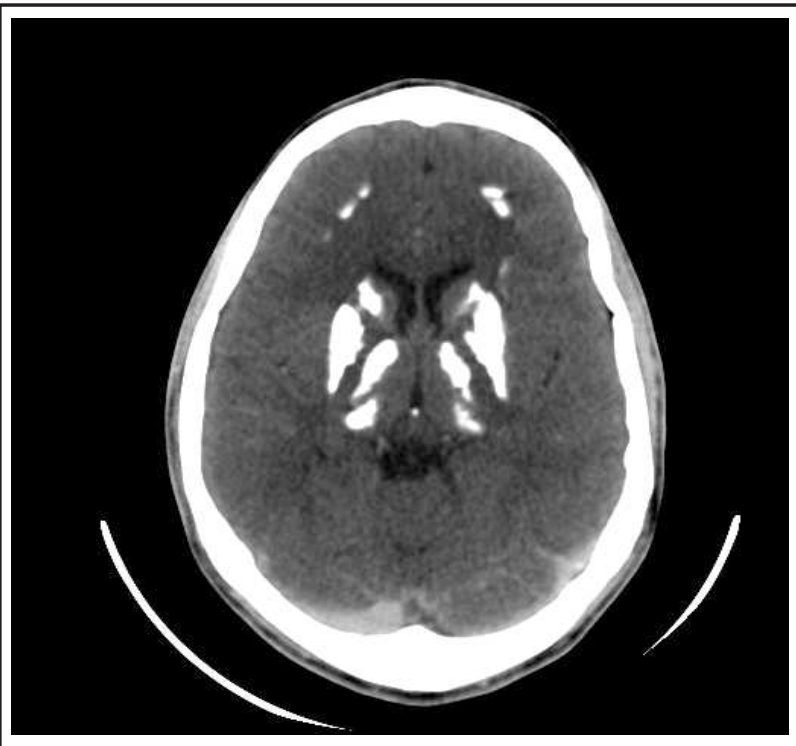

Figure 1. CECT brain axial section shows dense calcification in head of caudate nucleus, basal ganglia, thalamus and frontal cortex.

Patient was treated with sodium valporate, olanzapine. Patient improved significantly with these medications. However, patient came to follow-up after 6 months with exacerbation of signs and symptoms after stoppage of treatment. Patient was restarted with same treatment and is kept on OPD follow up.

\section{DISCUSSION}

Fahr Disease is a rare degenerative neurological disorder characterized by the presence of abnormal calcium deposition and associated cell loss in the areas of brain that control movement, including basal ganglia and cerebral cortex. ${ }^{2}$

The disease was first noted by German neurologist Karl Theodor Fahr in 1930. It may occur in a sporadic or familial manner. ${ }^{3,4}$ True prevalence of Fahr's disease is unknown. Typically, the age at onset of clinical symptoms is $30-60$ years. The clinical evolution is that of a degenerative disorder rather than a developmental disorder. $^{2}$
FD is characterized by clinical heterogeneity and can be asymptomatic (more frequent among middle-aged patients) or associated with neuropsychiatric manifestations..$^{3-7}$ The physiopathological mechanism of FD is not completely understood. Anatomopathological alterations mainly were observed in small vessels, perivascular regions, neuroglia and neurons. ${ }^{3,7}$ Fahr's disease, however, needs to be distinguished from Fahr's syndrome in which basal ganglia calcification is secondary to other disorders such as hypoparathyroidism. ${ }^{8,9}$ Basal ganglia calcification can also be seen in other conditions like endocrinopathies, systemic diseases, infections, primary and secondary calcified brain tumours and various other diseases.

The main neurological manifestations of FD include motor disorders such as parkinsonism, dystonia, tics, speech alterations, Epilepsia, and motor deficits which are probably due to involvement of the fronto-striatal motor system. ${ }^{3,4,10}$ The most frequent neuropsychiatric syndromes associated with FD are schizophrenia-like psychosis, mood and personality disorders, obsessivecompulsive symptoms and cognitive disorders notably executive dysfunctions.

CT scan is considered to be the best modality of investigation in the diagnosis of Fahr's disease where unenhanced $\mathrm{CT}$ reveals dense calcifications within the basal ganglia, subcortical white matter of the posterior parietal lobes and the dentate nuclei of the cerebellum. Additionally no contrast enhancement is found in these areas. ${ }^{11}$

There is neither specific cure for Fahr's disease, nor a standard treatment. Case reports have suggested that haloperidol, lithium carbonate may help patients with psychotic symptoms. ${ }^{12}$

In our case, patient presented with manic symptoms. All the common causes of Fahr's syndrome were excluded and CT scan showed classical dense calcification in head of caudate nucleus, basal ganglia, thalamus and frontal cortex. This rare case of Fahr's disease presenting with Manic symptoms which has never been reported in the Indian literature, has been presented to highlight this unusual presentation and it's differentiation from common Fahr's syndrome.

\section{Conflicts of Interest: None.}

Consent: JNMA Case Report Consent Form was signed by the patient and the original is attached with the patient chart. 


\section{REFERENCES}

1. Cummings JL, Gosenfeld LF, Houlihan JP, McCaffrey T. Neuropsychiatric disturbances associated with idiopathic calcification of the basal ganglia. Biol Psychiatry. 1983; 18:591-601. [ [ PubMed]

2. Malik R, Pandya VK, Naik D. FAHR disease : A rare neurodegenerative disorder. Indian $\mathrm{J}$ Radiol Imaging. 2004;14:383-4. [Full Text | DOI]

3. Chevalier D, Tillon J. A cause of cerebral calcifications not to be ignored: Fahr syndrome. Rev Med Interne. 2005;26:668-677. [Full Text]

4. Manyam BV. What is and what is not "Fahr's disease". Parkinsonism Relat Disorder. 2005;11:73-80. [Full Text]

5. Kummer A, Castro M, Carameli P, Cardoso F, Teixeira AL. Alterações comportamentais graves em paciente com doença de Fahr. Arq Neuropsiquiatr. 2006;64:645-649. [Full Text]

6. Tedrus GMAS, Fonseca LC, Nogueira EJ. Basal ganglia calcification on computed tomography: clinical characteristics in 25 patients. Arq Neuropsiquiatr. 2006;64:645-649. [Full Text]
7. Cartier RL, Passig VC, Gormaz WA, López CJ. Cambios neuropsicológicos en la enfermidad de Fahr. Rev Méd Chile. 2002;130:1383-1390. [Full Text]

8. Guerreiro MM, Scotoni AE. Calcifi cações dos gânglios da base na infância. Arq Neuropsiquiatr. 1992;50:513-8. [PubMed]

9. Oliveira JR, Spiteri E, Sobrido MJ, et al. Genetic Heterogeneity in Familial Idiopathic Basal Ganglia Calcification (Fahr disease). Neurology. 2004;63:2165-7. [PubMed | Full Text]

10. Weissman DC, Yaari R, Hansen LA, Thal LJ. Density of brain, decline of the mind (an atypical case of Fahr disease). Arch Neurol. 2007;64;756. [Full Text]

11. Scotti G, Scialfa G, Tampieri D, Landoni L. MR imaging in Fahr disease. J Comput Assist Tomogr. 1985;9:790-792. [Full Text]

12. Munir KM. The Treatment of psychotic symptoms in Fahr's disease with lithium carbonate. J Clin Psychopharmacol. 1986;6(1):36-8. [ubMed | Full Text] 